Check for updates

Cite this: RSC Adv., 2017, 7, 32139

Received 29th May 2017

Accepted 19th June 2017

DOI: 10.1039/c7ra06021a

rsc.li/rsc-advances

\section{KCC-1/GMSI/VB12 as a new nano catalyst for the carbonylative Suzuki-Miyaura crosscoupling reaction}

\author{
Seyed Mohsen Sadeghzadeh, (DD *a Rahele Zhiani ${ }^{\mathrm{ab}}$ and Shokufe Emrani ${ }^{\mathrm{ab}}$ \\ In this study, vitamin B12 (VB12) modified with a (3-glycidyloxypropyl)trimethoxysilane (GMSI) moiety \\ grafted onto KCC-1 (KCC-1/GMSI/VB12) was prepared for the first time. Its capability was evaluated for \\ the carbonylative Suzuki-Miyaura crosscoupling reaction between carbon monoxide, 4-iodoanisole and \\ phenylboronic acid, affording the desired products in high yield. Applying $1 \mathrm{mg}$ of catalyst and $1 \mathrm{mmol}$ of \\ $\mathrm{K}_{2} \mathrm{CO}_{3}$ as base in $10 \mathrm{~mL}$ anisole and heating under reflux for $1 \mathrm{~h}$ are the best conditions for the reaction. \\ The catalysts were very active in catalytic recycling experiments over ten catalytic cycles.
}

\section{Introduction}

The Suzuki coupling reaction has been shown to be an efficient method for the construction of $\mathrm{C}-\mathrm{C}$ bonds and plays an important role in the pharmaceutical industry and organic synthesis. Biaryl ketones are multipurpose building blocks in the field of pharmaceuticals, natural products, agrochemicals and biologically active compounds. ${ }^{\mathbf{1 , 2}}$ Among them, the Suzuki carbonylative coupling reaction is one of the most promising methods for the direct synthesis of biaryl ketones from carbon monoxide, aryl halides and arylboronic acids, since a wide variety of functionalities can be tolerated on either partner and the arylboronic acids are generally nontoxic and thermally-, airand moisture-stable. ${ }^{3-9}$

The ability of vitamin B12 to catalyse these thermodynamically challenging reactions has attracted the attention of synthetic chemists. Vitamin B12 is as an environmentally benign catalyst in organic reactions, which has eventually led to the discovery of new catalytic transformations. Vitamin B12 is as a catalyst which need costly and difficult separation of the catalyst from homogeneous reaction mixtures. For solving this problem, the use of heterogeneous vitamin B12 is important advantages in organic synthesis, such as operational simplicity, reusability, non-toxicity, environmental adaptability, and ease of isolation. The use of recyclable strong heterogeneous vitamin B12 in organic reactions are often considered to follow the principles of green chemistry, such as operational simplicity, reusability, non-toxicity, environmental adaptability, and ease of isolation. Recently, Vivek Polshettiwar reported the synthesis of new fibrous silica nanosphere (KCC-1) with high surface area,

${ }^{a}$ Department of Chemistry, Faculty of Sciences, Neyshabur Branch, Islamic Azad University, Neyshabur, Iran.E-mail: seyedmohsen.sadeghzadeh@gmail.com

${ }^{b}$ Young Researchers and Elite Club, Neyshabur Branch, Islamic Azad University, Neyshabur, Iran

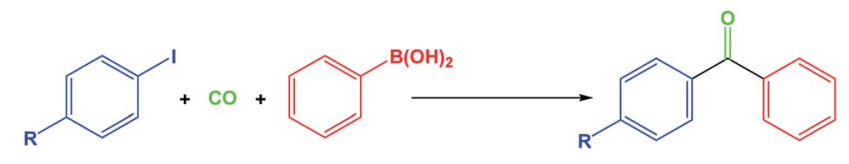

Scheme 1 Carbonylative Suzuki-Miyaura coupling

large open pore structure, and high thermal and hydrothermal stabilities. ${ }^{\mathbf{1 0}}$ Therefore, most of its surface area is accessible, yielding unusually high activity in catalysis. ${ }^{11-25}$ The KCC-1 is extremely favorable in the design of the inorganic-organic hybrid sensing materials owing to the unique physical properties such as easily accessible of active sites, large open pore structure, excellent solvent dispersibility, favorable biocompatibility, high surface area, and superparamagnetism. Herein, we present a facile synthesis of KCC- 1 based nanoparticles and was further functionalized by a vitamin B12 with (3-glycidyloxypropyl)trimethoxysilane (GMSI) linker that have been applied as novel nano catalyst for the carbonylative Suzuki-Miyaura crosscoupling reaction (Scheme 1).

\section{Experimental}

\section{Materials and methods}

Chemical materials were purchased from Fluka and Merck in high purity. Melting points were determined in open capillaries using an Electrothermal 9100 apparatus and are uncorrected. FTIR spectra were recorded on a VERTEX 70 spectrometer (Bruker) in the transmission mode in spectroscopic grade $\mathrm{KBr}$ pellets for all the powders. The particle size and structure of nano particle was observed by using a Philips CM10 transmission electron microscope operating at $100 \mathrm{kV}$. Powder X-ray diffraction data were obtained using Bruker D8 Advance model with $\mathrm{Cu} \mathrm{K} \alpha$ radiation. The thermogravimetric analysis (TGA) 
was carried out on a NETZSCH STA449F3 at a heating rate of $10{ }^{\circ} \mathrm{C} \mathrm{min}^{-1}$ under nitrogen. ${ }^{1} \mathrm{H}$ and ${ }^{13} \mathrm{C}$ NMR spectra were recorded on a BRUKER DRX-300 AVANCE spectrometer at 300.13 and 75.46 MHz, BRUKER DRX-400 AVANCE spectrometer at 400.22 and $100.63 \mathrm{MHz}$, respectively. Elemental analyses for $\mathrm{C}, \mathrm{H}$, and $\mathrm{N}$ were performed using a Heraeus $\mathrm{CHN}-\mathrm{O}-\mathrm{Rapid}$ analyzer. The purity determination of the products and reaction monitoring were accomplished by TLC on silica gel polygram SILG/UV 254 plates. Mass spectra were recorded on Shimadzu GCMS-QP5050 Mass Spectrometer.

\section{General procedure for the preparation of KCC-1 nanoparticles}

In order to synthesize KCC-1, at first cetyltrimethyl ammonium bromide (CTAB $1 \mathrm{~g}, 0.0027 \mathrm{~mol})$ and urea $(0.6 \mathrm{~g}, 0.01 \mathrm{~mol})$ was dissolved in deionized water. This solution was stirred for about $3 \mathrm{~h}$ until all of CTAB was dissolved. Then this solution was added to solution of tetraethyl orthosilicate (TEOS, $2.5 \mathrm{~g}, 0.012$ mol), cyclohexane (30 mL), and pentanol $(1.5 \mathrm{~mL})$. This mixture was stirred for $30 \mathrm{~min}$ at room temperature, and the resulting solution was refluxed at $120^{\circ} \mathrm{C}$ under stirring in oil bath for $4 \mathrm{~h}$. This solution placed in oven at $80{ }^{\circ} \mathrm{C}$ for $24 \mathrm{~h}$. Then the mixture was allowed to cool to room temperature and the silica formed was isolated by centrifugation (30 $\mathrm{min}, 6000 \mathrm{rpm})$, then washed with deionized water and acetone repeatedly and air-dried for $24 \mathrm{~h}$. The as-synthesized material was then calcined at $550{ }^{\circ} \mathrm{C}$ for six hours in air.

\section{General procedure for the preparation of KCC-1/GMSI NPs}

KCC-1 (2 mmol) and THF $(20 \mathrm{~mL})$ were mixed together in a beaker, and then $\mathrm{NaH}(20 \mathrm{mmol})$ was dispersed in to the mixture by ultrasonication. (3-Glycidyloxypropyl)trimethoxysilane (GMSI) (22 mmol) was added drop-wise at room temperature and stirred for another $16 \mathrm{~h}$ at $60{ }^{\circ} \mathrm{C}$. The resultant products were collected and washed with ethanol and deionized water in sequence, and then dried under vacuum at $60^{\circ} \mathrm{C}$ for $2 \mathrm{~h}$ for further use.

\section{General procedure for the preparation of KCC-1/GMSI/VB12 NPs}

KCC-1/GMSI (1 g), VB1 (1.5 mmol), and DMF (50 mL) were mixed together with magnetic stirrer bar. The reaction mixture was stirred for $5 \mathrm{~h}$ at $60{ }^{\circ} \mathrm{C}$ and was subsequently filtered and washed thoroughly with DMF, dried in oven at $60^{\circ} \mathrm{C}$ for $24 \mathrm{~h}$ to form the KCC-1/GMSI/VB12 NPs.

\section{General procedures for preparation of the carbonylative Suzuki reaction of aryl iodides}

To a $100 \mathrm{~mL}$ autoclave, aryl iodide $(1.0 \mathrm{mmol})$, aryl boronic acid (1.2 mmol), KCC-1/GMSI/VB12 (1 mg), anisole $(10 \mathrm{~mL})$ and $\mathrm{K}_{2} \mathrm{CO}_{3}(3 \mathrm{mmol})$ were added. The autoclave was closed, purged twice with $\mathrm{CO}$ gas, pressurized with $1 \mathrm{MPa}$ of $\mathrm{CO}$ and then heated under reflux for $1 \mathrm{~h}$. After completion of the reaction, the reaction mixture was cooled to room temperature and the remaining $\mathrm{CO}$ gas was carefully vented and the reactor was opened. Upon completion, the progress of the reaction was monitored by TLC when the reaction was completed, EtOH was added to the reaction mixture and the catalyst was separated by an external magnet. Then the solvent was removed from solution under reduced pressure and the resulting product purified by recrystallization using $n$-hexane/ethyl acetate.

\section{Results and discussion}

In this study, we have investigated the effect of KCC-1/GMSI/ VB12 NPs catalyst on the carbonylative Suzuki coupling reaction of iodobenzene with phenyl boronic acid. The VB12 functional groups in KCC-1/GMSI as a dendrimer could strongly favour the loading of VB12 due to the interaction between $\mathrm{OH}$ groups of VB12 and the internal epoxide groups of the dendrimer is believed to be the main reason for the loading of VB12 inside the dendrimer (Scheme 2).

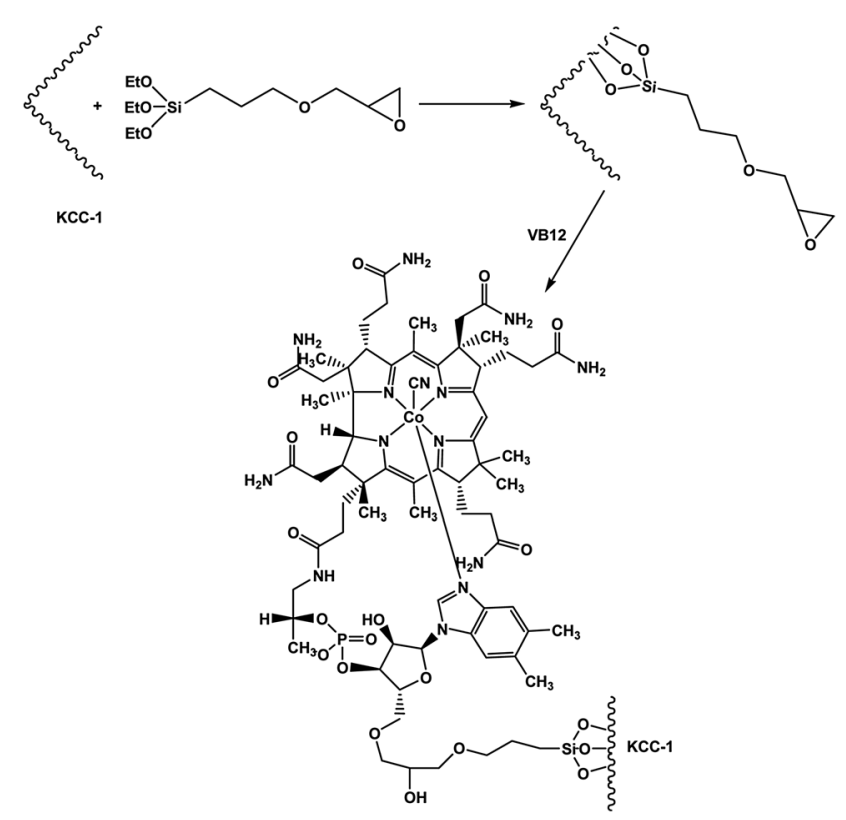

Scheme 2 Schematic illustration of the synthesis for KCC-1/GMSI/ VB12 NPs.

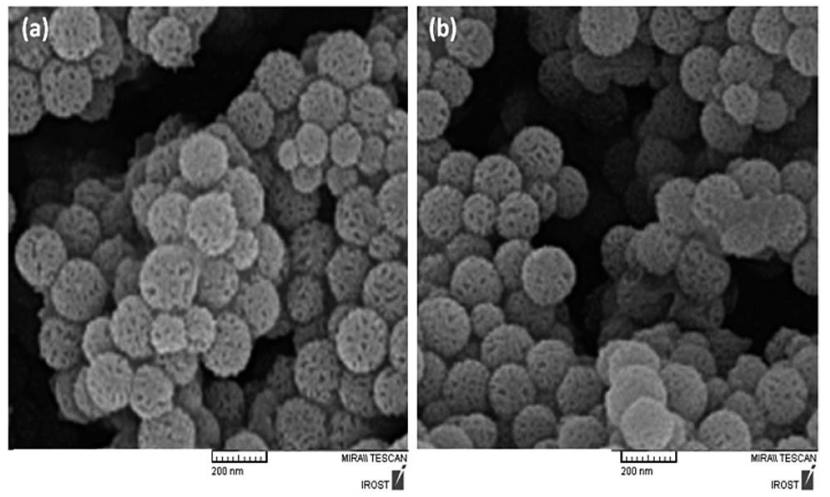

Fig. 1 SEM image of the fresh KCC-1/GMSI/VB12 NPs (a), and SEM images of KCC-1/GMSI/VB12 NPs after ten reuses (b). 
(c)

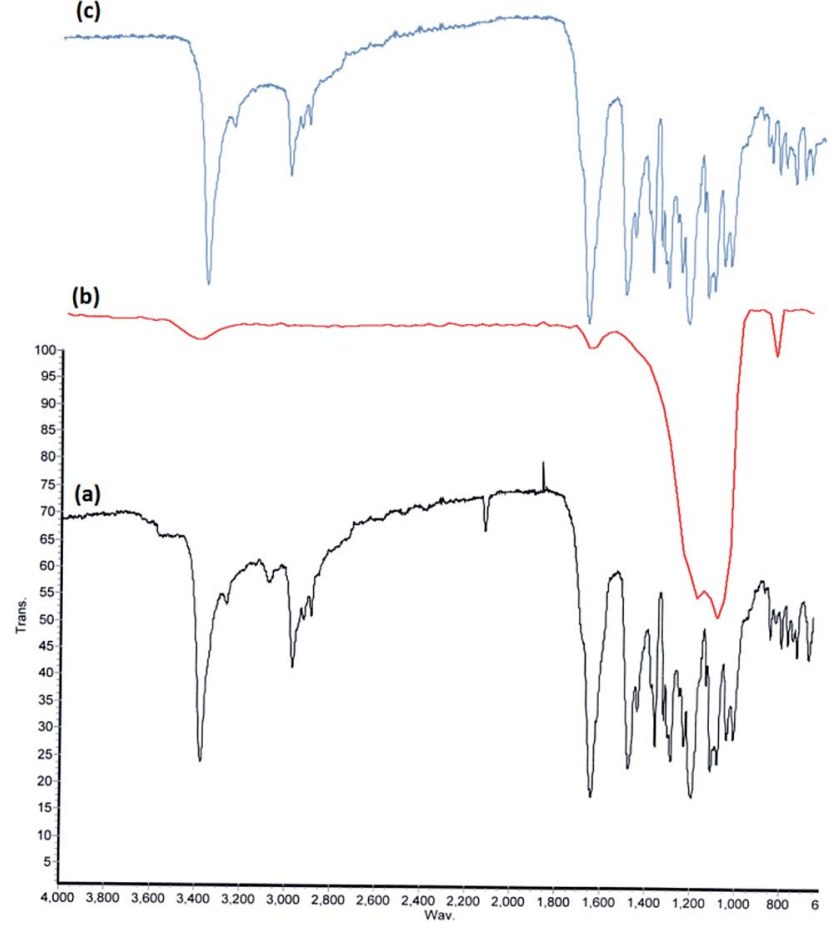

Fig. 2 FTIR spectra of vitamin B12 (a); KCC-1 (b); and KCC-1/GMSI/ VB12 NPs (c).

The SEM images of the KCC-1/GMSI/VB1 NPs catalysts were shown in Fig. 1. As can be seen from the Fig. 1a, the KCC-1/ GMSI/VB1 NPs had a consistent particle size range of 260$380 \mathrm{~nm}$. SEM image shown in Fig. 1a further clarifies that the distance between the two fibers was about 10-15 $\mathrm{nm}$. The recyclability test was stopped after ten runs. Comparison of SEM images of used catalyst (Fig. 1b) with those of the fresh catalyst (Fig. 1a) showed that the morphology and structure of KCC-1/GMSI/VB1 NPs remained intact after ten recoveries. Agglomeration of KCC-1/GMSI/VB1 NPs can not be seen.

FT-IR spectroscopy was employed to determine the surface modification of the synthesized catalyst (Fig. 2). The bands at 802,1103 and $1630 \mathrm{~cm}^{-1}$ observed in the FT-IR spectra of both KCC-1 is related to the typical silanol group ( $\mathrm{Si}-\mathrm{OH})$ stretching mode, $\mathrm{Si}-\mathrm{O}-\mathrm{Si}$ vibrations and the water absorbed on the solid

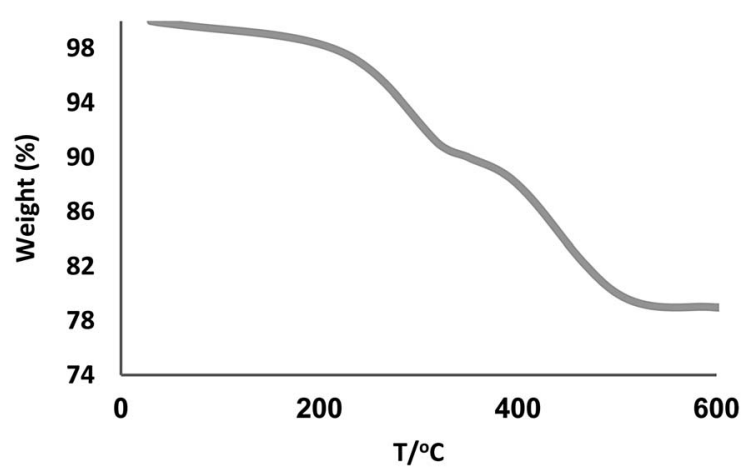

Fig. 3 TGA diagram of KCC-1/GMSI/VB12 NPs.
Table 1 Chemical composition of the reaction components using ICP

\begin{tabular}{lll}
\hline Entry & Element & Weight percent (\%) \\
\hline 1 & $\mathrm{Pd}$ & - \\
2 & $\mathrm{Cu}$ & $<0.01$ \\
3 & $\mathrm{Fe}$ & $<0.01$ \\
4 & $\mathrm{Ni}$ & - \\
5 & $\mathrm{Cd}$ & $<0.01$ \\
6 & $\mathrm{Co}$ & - \\
\hline
\end{tabular}

surface, respectively (Fig. 2b). FTIR spectrum of cobalamin is shown as a reference. The spectrum of VB12 shows two major parts. The broad peak at about $3400 \mathrm{~cm}^{-1}$ is assigned to the $\mathrm{O}-\mathrm{H}$ stretching of the hydroxyl groups attached to the surface. ${ }^{26}$ The second peak is in around of $1665 \mathrm{~cm}^{-1}$. The $\mathrm{C}=\mathrm{O}$ stretching vibration due to propionamide side chain of VB12 caused the appearance of this intense peak at $1670 \mathrm{~cm}^{-1}$ (Fig. 2a). ${ }^{27-29}$ Peak appeared at $3390 \mathrm{~cm}^{-1}, 3120 \mathrm{~cm}^{-1}, 2930$ $\mathrm{cm}^{-1}$, and $1665 \mathrm{~cm}^{-1}$ are due to the stretching of the hydroxyl group $(-\mathrm{OH})$, the $\mathrm{C}-\mathrm{H}$ aromatic group, the $\mathrm{C}-\mathrm{H}$ aliphatic group, and $\mathrm{C}=\mathrm{O}$ group in the KCC-1/GMSI/VB12 NPs (Fig. 2c). By comparing the three parts of Fig. 2, the formation of a new band at $751 \mathrm{~cm}^{-1}$ is evident. Although, this peak is situated in the fingerprint region of the IR spectrum, a new event is detected after the VB12 loading process, whereas no such peak is observed in the pristine VB12 and KCC-1 spectra. This phenomenon can be an evidence for the conjugation of VB12 molecules to KCC-1 NPs.

The TG analysis of KCC-1/GMSI/VB12 NPs was determined and shown in Fig. 3. A significant decrease in the weight percentage of the KCC-1/GMSI/VB12 NPs at about $130{ }^{\circ} \mathrm{C}$ is related to desorption of water molecules from the catalyst surface. This was evaluated to be $1-3 \%$ according to the TG analysis. In addition, the analysis showed two other decreasing peaks. First peak appears at temperature around $250-280{ }^{\circ} \mathrm{C}$ due to the decomposition of Co. This is followed by a second peak at $420-460{ }^{\circ} \mathrm{C}$, corresponding to the loss of the organic spacer group. The major concern is related with a plausible presence of trace amounts of other active metal (like Pd, Cu, Fe, $\mathrm{Ni}, \mathrm{Cd}$, and $\mathrm{Co}$ ) in any component of the reaction. To solve this problem it was necessary to carry out an ICP analysis of the reaction components. You can see in Table 1 that the concentration of $\mathrm{Pd}, \mathrm{Cu}, \mathrm{Fe}, \mathrm{Ni}, \mathrm{Cd}$, and Co were very low that discard the slightest doubt.

To optimize the reaction conditions, the carbonylative crosscoupling reaction of iodobenzene with phenyl boronic acid in the presence of KCC-1/GMSI/VB12 as a catalyst was chosen as a model system. The influence of various parameters such as solvent, base, and time (Table 2) were examined on the model reaction. The influence of solvents on the carbonylative Suzuki coupling reaction was investigated (Table 2, entries 1-15). According to the evaluated results of solvents, when polar protic solvents, such as methanol, isopropanol, ethanol, and water, were showed that any amount of the desired product was not formed. However, the yield of the cross-coupling product was 
Table 2 Carbonylative Suzuki-Miyaura reaction by KCC-1/GMSI/VB12 NPs in different solvents, bases, and time ${ }^{a}$

\begin{tabular}{|c|c|c|c|c|}
\hline Entry & Solvent & Base & Time (h) & Yield $^{b}(\%)$ \\
\hline 1 & EtOH & $\mathrm{K}_{2} \mathrm{CO}_{3}$ & 1.5 & - \\
\hline 2 & $\mathrm{H}_{2} \mathrm{O}$ & $\mathrm{K}_{2} \mathrm{CO}_{3}$ & 1.5 & - \\
\hline 3 & $\mathrm{CH}_{3} \mathrm{CN}$ & $\mathrm{K}_{2} \mathrm{CO}_{3}$ & 1.5 & 46 \\
\hline 4 & $\mathrm{DMF}$ & $\mathrm{K}_{2} \mathrm{CO}_{3}$ & 1.5 & 59 \\
\hline 5 & $\mathrm{CH}_{2} \mathrm{Cl}_{2}$ & $\mathrm{~K}_{2} \mathrm{CO}_{3}$ & 1.5 & 38 \\
\hline 6 & EtOAc & $\mathrm{K}_{2} \mathrm{CO}_{3}$ & 1.5 & 21 \\
\hline 7 & THF & $\mathrm{K}_{2} \mathrm{CO}_{3}$ & 1.5 & 32 \\
\hline 8 & Toluene & $\mathrm{K}_{2} \mathrm{CO}_{3}$ & 1.5 & 63 \\
\hline 9 & $n$-Hexane & $\mathrm{K}_{2} \mathrm{CO}_{3}$ & 1.5 & - \\
\hline 10 & $\mathrm{CHCl}_{3}$ & $\mathrm{~K}_{2} \mathrm{CO}_{3}$ & 1.5 & 32 \\
\hline 11 & DMSO & $\mathrm{K}_{2} \mathrm{CO}_{3}$ & 1.5 & 41 \\
\hline 12 & $\mathrm{MeOH}$ & $\mathrm{K}_{2} \mathrm{CO}_{3}$ & 1.5 & - \\
\hline 13 & Dioxane & $\mathrm{K}_{2} \mathrm{CO}_{3}$ & 1.5 & - \\
\hline 14 & i-PrOH & $\mathrm{K}_{2} \mathrm{CO}_{3}$ & 1.5 & - \\
\hline 15 & Anisole & $\mathrm{K}_{2} \mathrm{CO}_{3}$ & 1.5 & 96 \\
\hline 16 & Solvent-free & $\mathrm{K}_{2} \mathrm{CO}_{3}$ & 1.5 & - \\
\hline 17 & Anisole & - & 1.5 & - \\
\hline 18 & Anisole & $\mathrm{CsF}$ & 1.5 & - \\
\hline 19 & Anisole & $\mathrm{Na}_{2} \mathrm{CO}_{3}$ & 1.5 & 62 \\
\hline 20 & Anisole & $\mathrm{Et}_{3} \mathrm{~N}$ & 1.5 & - \\
\hline 21 & Anisole & NaOAc & 1.5 & - \\
\hline 22 & Anisole & $\mathrm{KOH}$ & 1.5 & 43 \\
\hline 23 & Anisole & $\mathrm{K}_{3} \mathrm{PO}_{4}$ & 1.5 & 70 \\
\hline 24 & Anisole & $\mathrm{Cs}_{2} \mathrm{CO}_{3}$ & 1.5 & 67 \\
\hline 25 & Anisole & $t \mathrm{BuOK}$ & 1.5 & - \\
\hline 26 & Anisole & $\mathrm{K}_{2} \mathrm{CO}_{3}$ & 1 & 96 \\
\hline 27 & Anisole & $\mathrm{K}_{2} \mathrm{CO}_{3}$ & 0.5 & 90 \\
\hline
\end{tabular}

${ }^{a}$ Reaction conditions: iodobenzene (1 mmol), phenyl boronic acid (1.2 $\mathrm{mmol}), \mathrm{KCC}-1 / \mathrm{GMSI} / \mathrm{VB} 12 \mathrm{NPs}(1 \mathrm{mg}), \mathrm{K}_{2} \mathrm{CO}_{3}(3 \mathrm{mmol})$, solvent $(10 \mathrm{~mL})$, $\mathrm{CO}$ pressure $=3 \mathrm{MPa} .{ }^{b}$ Isolated yields.

relatively average in polar aprotic solvents, such as DMF, $\mathrm{CH}_{2} \mathrm{Cl}_{2}$, EtOAc, $\mathrm{CHCl}_{3}$, anisole, and DMSO. When the reaction was conducted in less polar solvents, such as anisole or toluene, good to high yields of carbonylative cross-coupling product were isolated, and anisole was found to be the best choice. However, the carbonylative cross-coupling product was obtained in low yield in polar solvents. In this study, it was found

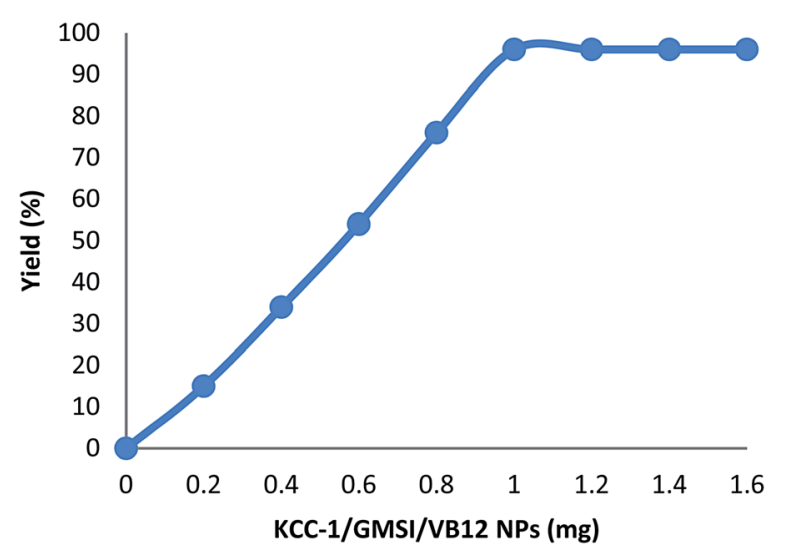

Fig. 4 Effect of increasing amount of KCC-1/GMSI/VB12 NPs on the preparation of vitamin $\mathrm{K} 3$.

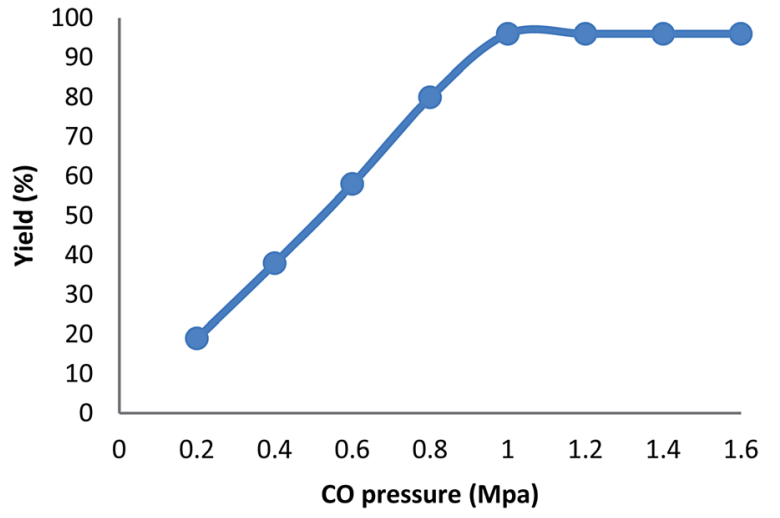

Fig. 5 Effect of pressure on yield of carbonylative Suzuki-Miyaura reaction.

that conventional heating under anisole is more efficient than using organic solvents (Table 2, entries 8). It is well known that bases play a crucial role in coupling reactions; hence we attempted the reaction in the presence of various organic and inorganic bases (Table 2, entries 16-26). As a result, the most used base $\mathrm{K}_{2} \mathrm{CO}_{3}$ was the most efficient base to produce carbonylative cross-coupling product. Under the optimal conditions, the reaction progress for the shortest time necessary in the presence of $2 \mathrm{mg}$ of KCC-1/GMSI/VB12 NP was monitored by GC, that excellent yields of carbonylative Suzuki coupling reaction can be achieved in $1 \mathrm{~h}$ (Table 2, entries 26).

We also study the decisive role of temperature in the synthesis of carbonylative Suzuki-Miyaura reaction in the presence of KCC-1/GMSI/VB12 NPs as a catalyst. The best temperature for this reaction heating under reflux do cause changes in the efficiency of the reaction, that showed the catalytic activity is susceptible to reaction temperature. The catalyst loading is another important factor in current reaction for the carbonylative cross-coupling reaction (Fig. 4). As shown in Fig. 4, the low yield of carbonylative Suzuki-Miyaura reaction was gained when model reaction was performed in the absence of a catalyst. When $0.2-0.8 \mathrm{mg}$ of KCC-1/GMSI/ VB12 NPs were elaborated on sample reaction, moderate yields of carbonylative Suzuki coupling reaction were obtained. The best result was achieved when the model reaction was carried out in the presence of $1 \mathrm{mg}$ of KCC-1/GMSI/VB12 NPs. A rise in the catalyst amount showed no upgrading in the model reaction. In the absence of the catalyst no product was obtained. Effects of CO pressure in the presence of iodobenzene, phenyl boronic acid, and KCC-1/GMSI/VB12 NPs for $1 \mathrm{~h}$ was shown in Fig. 5. The catalyst mixture reaches an average of $>96 \%$ of conversion at 1 MPa pressure. No apparent by-products were observed by GC in all the experiments and carbonylative Suzuki-Miyaura reaction was obtained cleanly in $96 \%$ yield.

With the optimized reaction conditions, we extended the scope of carbonylative Suzuki reaction to a variety of different aryl iodides with phenyl boronic acids. As shown in Table 3, various electron-donating and electron-withdrawing groups 
Table 3 Carbonylative Suzuki coupling reaction of various aryl iodides with arylboronic acid in the presence of the KCC-1/GMSI/VB12 NPs ${ }^{a}$

\begin{tabular}{|c|c|c|c|}
\hline Entry & Aryl iodide & Product & Yield $^{b}(\%)$ \\
\hline
\end{tabular}

1<smiles>Ic1ccccc1</smiles><smiles>O=C(c1ccccc1)c1ccccc1</smiles>

96<smiles>Cc1ccc(C(=O)c2ccccc2)cc1</smiles>

2<smiles>Cc1ccc(I)cc1</smiles><smiles>COc1ccc(I)cc1</smiles><smiles>COc1ccc(C(=O)c2ccccc2)cc1</smiles>
90 3<smiles>O=[N+]([O-])c1ccc(I)cc1</smiles><smiles>O=C(c1ccccc1)c1ccc([N+](=O)[O-])cc1</smiles><smiles>O=C(c1ccccc1)c1ccc(Cl)cc1</smiles>

5<smiles>Clc1ccc(I)cc1</smiles><smiles>Cc1ccccc1I</smiles>

7<smiles>COc1ccccc1I</smiles>

8<smiles>Nc1ccccc1I</smiles><smiles>Cc1ccccc1C(=O)c1ccccc1</smiles><smiles>COc1ccccc1C(=O)c1ccccc1</smiles><smiles>Nc1ccccc1C(=O)c1ccccc1</smiles>

with appreciable yields. Iodobenzene reacted with phenyl boronic acid giving 96\% yield of benzophenone (Table 3, entry 1). It is worth noting that aryl iodides containing electronwithdrawing groups, such as $-\mathrm{Br},-\mathrm{Cl},-\mathrm{COCH}_{3}$ and $-\mathrm{NO}_{2}$, were found to be the more active than aryl iodides containing electron-donating groups, such as $-\mathrm{CH}_{3},-\mathrm{OCH}_{3}$ and $-\mathrm{NH}_{2}$.

For further investigation the efficiency of the catalyst, different control experiments were performed and the obtained information is shown in Table 4. Initially, a standard reaction was carried out using KCC-1 showed that any amount of the desired product was not formed after $1 \mathrm{~h}$ of reaction time (Table 4, entry 1). Also, when KCC-1/GMSI was used as the catalyst, a reaction was not observed (Table 4, entry 2). The GMSI could not give the satisfactory catalytic activity under mild reactions. We compared the results achieved in this work with elsewhere over many other similar catalysts. In contrast with the catalysts of VB12 as a homogeneous catalysis our catalyst requires similar condition for the carbonylative crosscoupling (Table 4, entries 3 and 5). Also, the activity and selectivity of nano-catalyst can be manipulated by tailoring chemical and physical properties like size, shape, composition and morphology. To assess the exact impact of the presence of KCC-1 in the catalyst, the KCC-1/GMSI/VB12 NPs compared with $\mathrm{SiO}_{2} / \mathrm{GMSI} / \mathrm{VB} 12$ NPs. To check this, we looked at $\mathrm{SiO}_{2} /$ GMSI/VB12 and KCC-1/GMSI/VB12 NPs, which have the same compositions and different structures. When $\mathrm{SiO}_{2} / \mathrm{GMSI} / \mathrm{VB} 12$ was used as the catalyst, the yield of the desired product was fair to average, but the yield for KCC-1/GMSI/VB12 was good (Table 4, entries 3 and 4).

We compared the catalytic performance of our catalyst with catalysts reported for carbonylative Suzuki coupling reaction (Table 5). Table 5 clearly demonstrates that the most favourable terms are required for carbonylative Suzuki coupling reaction, using KCC-1/GMSI/VB12 NPs, while an appropriate, highly perfect, performance of the present catalyst is observed for the reaction.

To obtain information about the heterogeneity or homogeneity

${ }^{a}$ Reaction condition: iodobenzene ( $\left.1 \mathrm{mmol}\right)$, phenyl boronic acid (1.2 $\mathrm{mmol}$ ), KCC-1/GMSI/VB12 NPs $(1 \mathrm{mg}), \mathrm{K}_{2} \mathrm{CO}_{3}(3 \mathrm{mmol})$, solvent (10 $\mathrm{mL}$ ), CO pressure $1 \mathrm{MPa}$ after 1 hour. ${ }^{b}$ Yield refers to isolated product.

such as $-\mathrm{CH}_{3},-\mathrm{OCH}_{3},-\mathrm{NH}_{2},-\mathrm{COCH}_{3},-\mathrm{NO}_{2},-\mathrm{Br}$ and $-\mathrm{Cl}$ on both aryl iodide and aryl boronic acid smoothly underwent carbonylative Suzuki coupling reaction giving desired products

Table 4 Influence of different catalysts for carbonylative Suzuki coupling reaction ${ }^{a}$

\begin{tabular}{llll}
\hline Entry & Catalyst & Catalyst loading & Yield $^{b}(\%)$ \\
\hline 1 & KCC-1 & $1 \mathrm{mg}$ & - \\
2 & KCC-1/GMSI & $1 \mathrm{mg}$ & - \\
3 & KCC-1/GMSI/VB12 & $1 \mathrm{~mol} \%$ & 96 \\
4 & $\mathrm{SiO}_{2} /$ GMSI/VB12 & $1 \mathrm{~mol} \%$ & 59 \\
5 & VB12 & $1 \mathrm{~mol} \%$ & 97
\end{tabular}

${ }^{a}$ Reaction conditions: iodobenzene $(1 \mathrm{mmol})$, phenyl boronic acid (1.2 $\mathrm{mmol}), \mathrm{K}_{2} \mathrm{CO}_{3}(3 \mathrm{mmol})$, solvent $(10 \mathrm{~mL})$, CO pressure $1 \mathrm{MPa}$ after 1 hour. ${ }^{b}$ Isolated yield.

of the catalytic reaction, hot filtration and mercury poisoning tests were carried out. At first, the relationship between the progress of reaction and time was maximum at the range of 3-6 h. Thus, we chose the point of $5 \mathrm{~h}$ for the following experiments. The catalyst was filtered out at above $100{ }^{\circ} \mathrm{C}$ after the reaction proceeded for $6 \mathrm{~h}$ and the yield of benzophenone was $74 \%$ determined by GC. The obtained filtrate with additional $1.0 \mathrm{mmol}$ phenyl boronic acid was continually stirred under the reaction conditions. After 6 hours the conversion was determined to be $74 \%$. The same approach was applied to mercury test. After the first stage, the yield of benzophenone was $72 \%$. In the second stage, after mercury $(0.3 \mathrm{~mL})$ was added into the filtrate, the filtrate was stirred for another six hours under the reaction conditions. The yield of benzophenone remained to be $74 \%$. These phenomena show that a small amount of catalytically active VB12 species may have leached to the reaction mixture (Fig. 6). But the contents of VB12 in catalyst before and after reaction were $5.7 \%$ and $5.5 \%$ respectively, determined by ICP-MS. These indicate that most of VB12 species leaching into solution are recaptured onto the fibers of KCC-1 after completion of the reaction (Table 6). It is important 
Table 5 Comparison of the catalytic efficiency of KCC-1/GMSI/VB12 NPs with various catalysts ${ }^{a}$

\begin{tabular}{|c|c|c|c|c|}
\hline Entry & Catalyst & Experimental conditions & Yield (\%) & Ref. \\
\hline 1 & $\mathrm{Pd} / \mathrm{C}$ & $100^{\circ} \mathrm{C}, 8 \mathrm{~h}, 4$ bar $\mathrm{CO}$ & 90 & 30 \\
\hline 2 & P(DVB-NDIIL)-Pd & $120^{\circ} \mathrm{C}, 12 \mathrm{~h}, 30$ bar CO & 86 & 31 \\
\hline 4 & PS-Pd-NHC & $100{ }^{\circ} \mathrm{C}, 10 \mathrm{~h}, 7$ bar CO & 94 & 33 \\
\hline 5 & HMMS-SH-Pd & $80^{\circ} \mathrm{C}, 9 \mathrm{~h}, 1$ bar CO & 94 & 34 \\
\hline 6 & MCM-41-2N-Pd & $80^{\circ} \mathrm{C}, 8 \mathrm{~h}, 1$ bar $\mathrm{CO}$ & 91 & 35 \\
\hline
\end{tabular}

${ }^{a}$ Reaction conditions: iodobenzene $(1.0 \mathrm{mmol})$, phenylboronic acid $(1.2 \mathrm{mmol})$, in different temperature, time, and pressure of CO.

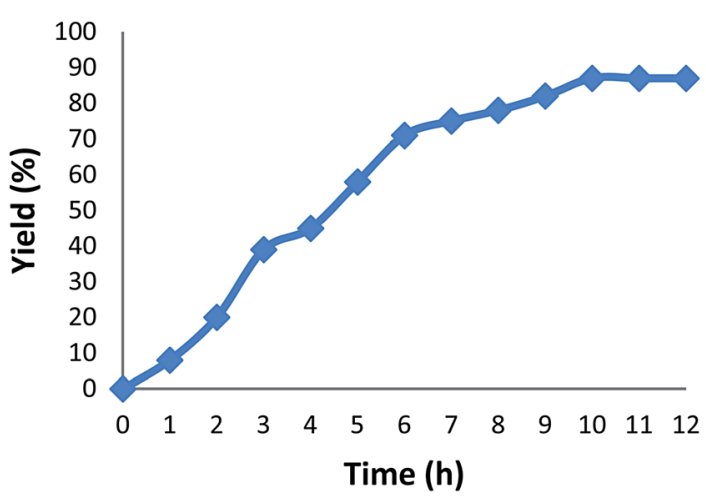

Fig. 6 Effect of time on yield of carbonylative Suzuki coupling reaction.

Table 6 The loading amount of VB12 in KCC-1/GMSI/VB12 NPs

\begin{tabular}{llc}
\hline Entry & Catalyst & wt $\%$ \\
\hline 1 & KCC-1/GMSI/VB12 NPs & 5.7 \\
2 & KCC-1/GMSI/VB12 NPs after ten reuses & 5.5
\end{tabular}

to note that the heterogeneous property of KCC-1/GMSI/VB12 NPs facilitates its efficient recovery from the reaction mixture after the completion of reaction. The amount of VB12 in KCC-1/GMSI/VB12 NPs were similar after reused for ten consecutive periods of catalysts. Notably, the catalyst could be recycled up to ten times with a marginal decrease in activity (Fig. 7).

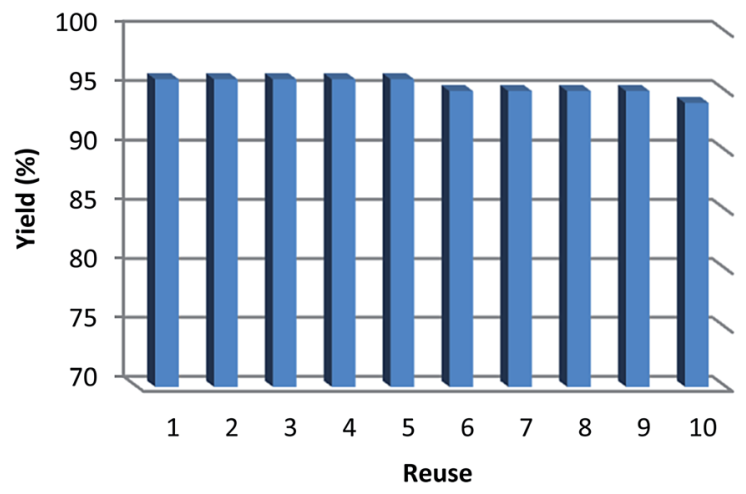

Fig. 7 Reuses performance of the catalysts.

\section{Conclusions}

In summary, a novel class of short-fiber KCC-1 mesoporous silica functionalized with 1,3-bis(dimethylthiocarbamoyloxy) benzene groups ligands was synthesized for selective capturing of VB12, that exhibited excellent catalytic activity for carbonylative Suzuki coupling reaction in good yields. FTIR, SEM, TGA, ICP-MS, and BET surface area analysis studies suggested the functionalization of VB12 in the surface of the mesopores silica. In addition, the catalyst was easily recoverable and reusable. Such a rational design for single-site catalysts with full utilization of each VB12 active site, as well as excellent recyclability and negligible catalyst leaching could coincide with the concepts of green chemistry. Thus, the study of KCC-1/GMSI/ VB12 nanocatalyst may provide a potential platform for the fabrication of other nano catalyst with easy accessibility, which would be highly efficient in various nano catalyst based catalytic reactions. This process may be used in the future to develop additional nanocatalysts that possess favorable properties, such as efficiency and ease of reuse.

\section{Notes and references}

1 P. J. Tambade, Y. P. Patil, A. G. Panda and B. M. Bhanage, Eur. J. Org. Chem., 2009, 3022-3025.

2 L. Kollar, Modern Carbonylation Methods, Wiley-VCH, Weinheim, 2008.

3 M. V. Khedkar, P. J. Tambade, Z. S. Qureshi and B. M. Bhanage, Eur. J. Org. Chem., 2010, 6981-6986.

4 Z. S. Qureshi, K. M. Deshmukh, P. J. Tambade and B. M. Bhanage, Synthesis, 2011, 2, 243-250.

5 S. Bonnaire, J. F. Carpentier, A. Mortreux and Y. Castanet, Tetrahedron, 2003, 59, 2793.

6 A. Fihri, M. Bouhrara, B. Nekoueisharki, J. M. Basset and V. Polshettiwar, Chem. Soc. Rev., 2011, 40, 5181.

7 Q. Zhou, S. Wei and W. Han, J. Org. Chem., 2014, 79, 14541460.

8 Y. Zhong, X. Gong, X. Zhu, Z. Ni, H. Wang, J. Fu and W. Han, RSC Adv., 2014, 4, 63216-63220.

9 L. Cheng, Y. Zhong, Z. Ni, H. Du, F. Jin, Q. Rong and W. Han, RSC Adv., 2014, 4, 44312-44316.

10 V. Polshettiwar, D. Cha, X. X. Zhang and J. M. Basset, Angew. Chem., Int. Ed., 2010, 49, 9652-9656. 
11 A. S. Lilly Thankamony, C. Lion, F. Pourpoint, B. Singh, A. J. Perez Linde, D. Carnevale, G. Bodenhausen, H. Vezin, O. Lafon and V. Polshettiwar, Angew. Chem., Int. Ed., 2015, 54, 2190-2193.

12 M. Bouhrara, C. Ranga, A. Fihri, R. R. Shaikh, P. Sarawade, A. H. Emwas, M. N. Hedhili and V. Polshettiwar, ACS Sustainable Chem. Eng., 2013, 1, 1192-1199.

13 M. Dhiman, B. Chalke and V. Polshettiwar, ACS Sustainable Chem. Eng., 2015, 3, 3224-3230.

14 A. Fihri, M. Bouhrara, D. Cha, N. Almana and V. Polshettiwar, ChemSusChem, 2012, 5, 85-89.

15 A. Fihri, M. Bouhrara, U. Patil, D. Cha, Y. Saih and V. Polshettiwar, ACS Catal., 2012, 2, 1425-1431.

16 V. Polshettiwar, J. Thivolle-Cazat, M. Taoufik, F. Stoffelbach, S. Norsic and J. M. Basset, Angew. Chem., Int. Ed., 2011, 50, 2747-2751.

17 X. Le, Z. Dong, Y. Liu, Z. Jin, T. D. Huy, M. Leb and J. Ma, J. Mater. Chem. A, 2014, 2, 19696-19706.

18 X. Le, Z. Dong, X. Li, W. Zhang, M. Le and J. Ma, Catal. Commun., 2015, 59, 21-25.

19 H. Yang, S. Li, X. Zhang, X. Wang and J. Ma, J. Mater. Chem. A, 2014, 2, 12060-12067.

20 R. Singh, R. Bapat, L. Qin, H. Feng and V. Polshettiwar, ACS Catal., 2016, 6, 2770-2784.

21 Z. Sun, H. Li, D. Guo, J. Sun, G. Cui, Y. Liu, Y. Tian and S. Yan, J. Mater. Chem. C, 2015, 3, 4713-4722.

22 K. Yu, X. Zhang, H. Tong, X. Yan and S. Liu, Mater. Lett., 2013, 106, 151-154.
23 Z. Dong, X. Le, C. Dong, W. Zhang, X. Li and J. Ma, Appl. Catal., B, 2015, 162, 372-380.

24 Z. Dong, X. Le, X. Li, W. Zhang, C. Dong and J. Ma, Appl. Catal., B, 2014, 158-159, 129-135.

25 X. Le, Z. Dong, W. Zhang, X. Li and J. Ma, J. Mol. Catal. A: Chem., 2014, 395, 58-65.

26 M. Gharagozlou and R. Bayati, Mater. Res. Bull., 2015, 61, 340-347.

27 L. Jin, P. Lu, H. You, Q. Chen and J. Dong, Int. J. Pharm., 2009, 371, 82-88.

28 K. S. Taraszka, E. Chen, T. Metzger and M. R. Chance, Biochemistry, 1991, 30, 1222-1227.

29 M. Gharagozlou and S. Naghibi, Mater. Res. Bull., 2016, 84, 71-78.

30 M. V. Khedkar, P. J. Tambade, Z. S. Qureshi and B. M. Bhanage, Eur. J. Org. Chem., 2010, 6981-6986.

31 N. Jiao, Z. Li, Y. Wang, J. Liu and C. Xia, $R S C A d v ., 2015$, 5, 26913-26922.

32 X. Sun, Y. Zheng, L. Sun, Q. Lin, H. Su and C. Qi, Nano-Struct. Nano-Objects, 2016, 5, 7-14.

33 M. Deshmukh, P. J. Tambade and B. M. Bhanage, Synthesis, 2011, 2, 0243-0250.

34 J. Niu, M. Liu, P. Wang, Y. Long, M. Xie, R. Li and J. Ma, New J. Chem., 2014, 38, 1471-1476.

35 M. Cai, J. Peng, W. Hao and G. Ding, Green Chem., 2011, 13, 190-196. 